\title{
A CULTURA ROMANA E OS POVOS DO NORTE EUROPEU
}

\author{
Maria Isabel D'Agostino Fleming \\ Museu de Arqueologia e Etnologia \\ Universidade de São Paulo
}

Resumo: Os testemunhos arqueológicos do final da República e início do Império romanos revelam uma enorme massa de material romano encontrado nas áreas ocupadas pelas tribos da Germánia Livre. Tais achados, em grande parte artigos de luxo, se adensam à medida que se distanciam do Limes. Alguns estudos que abordam a questão do contato cultural, de uma forma que não a tradicional (Rowlands, 1987; Hedeager, 1987; Renfrew, 1986), propõem uma interpretação que, se não minimiza a presença romana nessas áreas, dão uma nova dimensão ao processo de mudança cultural local. Dessa forma, na abordagem dos objetos de prestígio romanos entre esses povos, o contato entre romanos e germánicos é visto como estímulo para uma mudança social significativa cujas raízes já se encontravam na própria estrutura local.

Palavans-chave: Arqueologia Romana e do Norte Europeu, Mudança Cultural, Economia, Comércio, Bens de Prestígio.

A questão do contato entre culturas é tratada pela História e Arqueologia tradicionais sob o ponto de vista do poder dominante. Um exemplo é o dos povos do leste e norte da fronteira do Reno, retratados não como entidades culturais ativas em seus próprios direitos mas, predominantemente, através de suas reações à cultura romana ${ }^{1}$. As teorias arqueológicas recentes vêem 0 contato entre povos e a mudança cultural sob uma otica que redimensiona o papel dos grandes centros e das comunidades periféricas, sobretudo numa suposta relação de dependência evidente destas últimas. Ao mesmo tempo, na abordagem do problema do crescimento de sistemas sócio-politicos e da emergência da complexidade cultural, a interação entre unidades sócio-politicas autônomas adquire um papel primordial e abrangente: designa toda a gama de trocas, incluindo imitação e emulação, competição, guerra, troca de bens e de informação ${ }^{2}$. Assim, na história do

1. Dos estudos relevantes sobre a Germånia Livre destacam-se os de H. J. Eggers, Der Römische Import in Freien Germanien e de M. Wheeler, Rome Beyond the Imperial Frontiers. Da década de 50, são obras de referência indispensáveis tanto para os contextos arqueológicos em que foram encontradas as importaçōes romanas, como para a análise das fontes literárias sobre esse material.

2. Essas linhas de pesquisa são propostas nos estudos teóricos de C. Renfrew, "Introduction: peer polity interaction and socio-political change" e de M. Rowlands, "Centre and periphery: a review of a concept", e pode-se testemunhar sua aplicação em estudos de caso, como, por exemplo, 0 de L. Hedeager, "Empire, frontier and the barbarian hinterland: Rome and northern Europe from AD 1-400" e 0 de P. S. Wells, "Tradition, Identity, and Change beyond the Roman Frontier". Este artigo, em suas linhas gerais, baseia-se no trabalho de Hedeager por ser uma autora que de maneira sistemática e exaustiva vem se 
desenvolvimento sócio-político germânico, é fundamental considerar os dois tipos de relações envolvidos: a romano-germânica e a das várias comunidades germânicas entre si.

Nos contatos entre os romanos e povos da Germânia Livre entre 1 e 400 $A D$, são de especial interesse os milhares de produtos romanos que chegaram além das fronteiras do Império: eles incluem cerâmica fina, vasos de prata e bronze, vidros, jóias, moedas e estatuetas de bronze. A escala de importação do vinho é incerta, como também a de produtos exóticos, como frutas do Mediterrâneo e especiarias. Os produtos importados, ou seja, transmitidos através de interação, nos seus aspectos sociais e políticos, sã̃o intermediários nas relações entre indivíduos e grupos; eles indicam as formas como as sociedades são organizadas e as formas nas quais os indivíduos e os grupos se interrelacionam. Eles ajudam a definir relações e ao mesmo tempo simbolizam essas mesmas relações. Assim, através do estudo dos bens envolvidos, pode-se investigar ao mesmo tempo a manifestação da interação e um componente essencial dessa interação (Wells, 1992, p. 176). Tanto as importações romanas quanto as estruturas arqueológicas da Germânia Livre, ao serem analisadas, proporcionam 0 quadro das mudanças sociais, políticas e econômicas por que passaram esses povos.

Tendo em vista os diferentes níveis de complexidade sócio-políticoeconômica dos povos ao norte da Itália, incorporados ou não ao Império, a análise de sua interação com os romanos deve considerar três estruturas diferentes. Essa divergência estrutural determinou o curso da expansão romana. Ela, em geral, parou na fronteira entre a sociedade celta mais altamente estratificada e a sociedade germânica menos estratificada:

1. Um sistema romano sobre uma base celta, o resultado da expansão romana em áreas anteriormente celtas com uma "civilização arcaica" altamente desenvolvida que foram incorporadas ao Império romano.

2. Um sistema anterior celta com reinos vassalos além da fronteira que atuava como uma zona tampão entre o Império romano e as tribos germânicas.

3. 0 sistema germânico, baseado num curso de desenvolvimento germânico independente mediado, particularmente a partir de 100 a. C., através do contato com a região celta.

Os dois sistemas da periferia romana também têm economias totalmente diferentes:

1. O Império romano caracterizado por uma economia monetária e de mercado.

2. A "zona tampão" que não tinha uma cunhagem independente, mas mantinha uma economia monetária limitada, talvez incluindo mercados e uma classe de comerciantes. 
3. A Germânia Livre, que usava moeda sem uma economia monetária e talvez mercados sem moedas.

As evidências arqueologicas de relações de comércio e troca encontramse em toda a parte, mas sua distribuiç̧ão ao norte do Limes não é uniforme. Na região da fronteira, numa faixa de $200 \mathrm{Km}$ que acompanha o Limes há uma preponderância de artigos de uso diário, como cerâmica e vários tipos de broches. Esse material diminui à medida que cresce a distância da fronteira, enquanto, inversamente, para os artigos de luxo, como vasilhas de prata, bronze e vidros, seu número aumenta e atinge seu máximo numa diståncia de 400-600 Km da fronteira (ver figuras $1 \mathrm{e} 2$ ).

Enquanto o motivo romano para essa troca era um misto de interesses políticos e econômicos (paz ao longo da fronteira, ganho econômico), as tribos germånicas estavam preocupadas com a aquisição de artigos de luxo, moedas de ouro e prata, porque, juntamente com as armas, eles eram importantes símbolos de status no sistema social germânico.

As implicações sociais desses artefatos romanos no contexto germânico são expressas mais claramente através de seu uso como mobiliário funerário. Por exemplo, nas chamadas tumbas principescas do início do Império, num total de vinte e cinco, espalhadas em uma vasta região do interior da Germânia, numa distância acima dos $200 \mathrm{Km}$ da fronteira (Alemanha, Polônia, Tchecoslováquia, Dinamarca e Noruega).

A distribuição das tumbas principescas é complementar ao antigo território celta demarcado pelos grandes oppida celtas. Nessa região as importações romanas não serviam como indicadores de status, seja em qualquer tipo de tumbas mais ou menos ricas: a cerâmica romana, broches, moedas de cobre e inscrições, simplesmente expressam a proximidade dos romanos.

A presença de produtos de luxo romanos em tumbas germânicas, datadas dos séculos I e II d. C., é um fator indicativo de mudanças que ocorreram ao longo do Império e que podem ser vistas em dois períodos: 1-200 AD e 200-400 $A D$.

No primeiro período, as terras bárbaras constituíam uma espécie de equilíbrio econômico e político em relação ao Império. Exportando excedentes baratos - provavelmente para 0 exército - o povo germánico ajudou a financiar 0 sistema de defesa da fronteira norte, até o momento em que os produtos romanos preencheram um lugar importante na estrutura social e politica das tribos germânicas. As relaçōes comerciais romano-germânicas pareciam ser em favor dos romanos, tanto econômica quanto politicamente. No entanto, a longo prazo, foi uma política com riscọs inerentes, pois acelerou a dinåmica interna da sociedade germânica $\mathrm{e}$, consequentemente, a demanda por importações entre as tribos germânicas.

Assim, o lugar ocupado pelos produtos romanos no desenvolvimento interno das sociedades germânicas de $1 \mathrm{a} 400 \mathrm{AD}$ merece ser visto em maior detalhe:

a. em que medida os produtos romanos alargaram 0 alcance dos desenvolvimentos internos? 
b. eles substituiram outros bens de prestigio ou introduziram um conjunto mais elaborado de valores simbólicos e ideológicos romanos?

c. valores que poderiam ser usados por uma elite local para estabelecer e consolidar poder e prestigio?

Confrontando o contexto principesco germânico do Império romano com 0 de um período mais recuado da Idade do Bronze germânica (200 a. C.) obtém-se indicios para as respostas às questões acima. Na Idade do Bronze germânica, raramente o material de luxo importado (grego, etrusco, celta e republicano romano) destinou-se a enterramentos, mas a depósitos votivos, em contextos rituais. A partir do século I d. C., portanto no Império romano, os objetos de prestígio aparecem em enormes quantidades nos mobiliários funerários. 0 fator decesivo nessas importações era a quantidade. Há um claro contraste entre a situação anterior que evidenciava práticas comunitárias, com a situação do período imperial romano que realça a importância do indivíduo na sociedade.

A grande quantidade de bens valiosos não estimulou, surpreendentemente, uma acumulação na forma de tesouros ou depósitos, apesar da vasta rede de contatos comerciais através do mundo germânico. Esse fato corrobora a idéia de que as importações não tinham um valor de troca. Elas eram a expressão simbólica, tangivel de alianças tanto sociais como políticas, cujo significado era pessoalmente ligado ao indivíduo, portanto, não circulavam. Tais importações não eram tanto a evidência de riqueza material mas, primordialmente, conexões e alianças politicas acentuadas e indicavam algum conhecimento do modo de vida romano.

As análises cronologicas dos dois primeiros séculos do Império mostraram um aumento significativo na estratificação social - mais riqueza sendo concentrada em menos enterramentos. 0 contato com o Império romano causou 0 desenvolvimento de uma organização militar nova, dinâmica, e este processo foi fortalecido pelo comércio e em troca com produtos de prestigio romanos.

No início do período entre 200 a $400 \mathrm{AD}$, dando continuidade ao processo em desenvolvimento visto acima, a centralização política tornou-se um fato estabelecido. Um único centro controlava agora, política e militarmente, grandes regiōes. Na Germânia Livre, isso se reflete numa forte concentração regional de ricas tumbas com produtos romanos importados, em contraposição à distribuição irregular do período precedente. Concomitantemente, nota-se uma redistribuição regional desses bens de prestígio que circulam entre uma nova elite ao lado da concentração espacial de tumbas ricas. Ou seja, eles são distribuidos entre uma gama maior de pequenos chefes pelo chefe maior em troca de bens e serviços. Essa distribuição tanto em tumbas modestas quanto em ricas, sugere que os objetos eram usados como uma forma visivel de larguesa real, dispensada por potentados em ascenção a seus partidários. As importações eram tanto parte do poder quanto signos dele.

Dessa forma, os produtos de prestígio romanos eram parte de um processo no qual o poder $e$ a influência foram criados e, em combinação com a expansão militar e econômica, trouxeram mudanças significativas ao quadro social e político da Germânia Livre em quatrocentos anos do Império romano. Durante esse 
período, o papel dos bens de prestígio romanos sofreu uma mudança - de uma elite autônoma, para uma distribuição regional.

Em relação à ocupação espacial e ao tipo de estabelecimento ou estruturas habitacionais, a organização da vida, com base comunitária do início do Império, com unidades produtivas num sistema de campo comum, desaparece no século III d. C. Essa mudança na organização da vila, revelada nas alterações no tamanho das habitações, estábulos e plano das vilas, aplica-se também à sua base produtiva de terra de cultivo e pastagem. 0 direito individual de cultivar os campos comuns da vila é substituído pelo direito de posse individual ou por título de posse.

A emergência de uma classe proprietária que controla a produção não deve ter ocorrido apenas através do domínio militar ${ }^{3}$. 0 meio deve ter sido uma legitimação maciça da ideologia de certos grupos de pessoas. Nesse contexto, as importações romanas preenchem as funçōes necessárias se 0 prestígio e 0 status devem ser enfatizados. Os bens de prestígio indicam a participação do indivíduo na larga rede de alianças políticas e ligações de comércio que, por sua vez, representam contato com o Império romano, o estilo de vida e normas romanos.

Além de elevar a posição social do proprietário, a mais importante função dos bens de prestígio é seu emprego na reprodução social. Eles poderiam circular como dotes, tributos e outras formas de pagamento. 0 controle sobre bens de prestígio, portanto, implica poder social e político, útil na negociação de alianças, por esse meio expandindo a base de poder político e econômico de uma chefia. Regionalmente, isso poderia ser feito estabelecendo dependência política e militar em forma de proteção oferecida em troca de tributos: serviço militar, escravos ou pagamentos em espécie, que deveriam ser bens de prestígio. Localmente, nas vilas, os bens de prestígio podem ter sido usados como meios de criar dependência econômica e social, gradualmente levando à entrega da terra e animais e ao status de escravo/servo. No limite, a intensificação desse processo é um fator que contribui na reorganização da posse da terra e reorganização da vila. A diminuição do número de unidades produtivas em uma vila poderia ser explicada por um processo desse tipo. Embora em menor número, as habitações tornaram-se maiores, com mais aposentos para as pessoas e animais, o que nos conduz à produção.

Para sustentar o sistema, era necessário um excedente na produção e também 0 controle da terra e dos que produziam a safra.

Assim, as sociedades germânicas no período de 1-400 $A D$ experimentaram um crescimento populacional, expansão de ocupação e aumento da demanda de excedente de produção para alimentar suas populações e pagar tributos que eram canalizados, em seguida, para alianças e comércio de longa distância de bens de prestígio romanos.

3. Essa legitimação da ordem sócio-politica também poderia incluir a legitimação de uma função militar. Não 6 exagero dizer que o poder militar era a base 8 o pré-requisito para o controle político interno. A legitimação ideológica era antes o resultado do prestigio latente na função militar (Hedeager, 1987, nota 14). 


\section{ConcLusio}

Nesses processos de mudança não estamos lidando com um fator isolado determinante, mas com a interação de muitos. A mais forte influência foram, sem dúvida, os processos sociais resultantes da conversão de bens de prestígio em poder político e econômico. Tais processos estavam ligados à organização da produção. Foram as mudanças na organização da produção que deram ao sistema uma nova base para expansão. Quando a terra tornou-se um produto de troca, estavam estabelecidas as condições para a formação de uma aristocracia agrária.

Mas ainda permanece a questão: 0 contato com o Império e o exército romanos é uma explicação suficiente para as profundas mudanças nas terras bárbaras a partir do século. III d. C.? Talvez seja mais adequado imaginar que as influências romanas agiram como um catalizador num processo que já tinha começado. Para determinar se esse é, de fato, o caso, temos que considerar a relação entre o fator interno: niveis de subsistência, e o fator externo: comércio de bens de prestígio.

Uma análise mais pormenorizada indica que todo o processo de uso de bens de prestígio, no entanto; teve lugar num contexto tradicional. As práticas de enterramento nas tumbas principescas eram específicas da sociedade local, e não emprestadas do Império. Tanto as estruturas das tumbas quanto oútrọs objetos que acompanhavam as importações romanas pertenciam às tradições regionais. As pessoas da elite que estavam utilizando as importações romanas para afirmar status e expressar novas identidades ligadas a Roma, não estavam tentando tornar-se romanas, mas usando sua conexão romana construída para vaantagens desfrutadas em suas próprias comunidades.

Abstract: Archaeological witnesses of the end of the Republic and beginning of the Roman Empire revealed a huge mass of roman material found in the areas occupied by the tribes of Free Germania. Such findings, largely luxury articles, become more frequent at sites further from the Limes. Some studies, which touch the question of cultural contact, in a form other than the traditional one (Rowlands, 1987; Hedeager, 1987; Renfrew, 1986), propose an interpretation which, though not minimizing the roman presence in the areas, give a new dimension to the process of local cultural change. In this way, in the study of the function of roman prestige objects ammong these peoples, the contact between Romans and German tribes is regarded as a stimulus for a significant social change whose roots were found already in local structure itself.

KEY-words: Roman and North-European Archaeology, Cultural Change, Economy, Commerce, Prestige Goods. 
Bibliografia

EGGERS, H. J. Der Römische Import in Freien Germanien. Hamburg, 1951.

HEDEAGER, L. Empire, frontier and the barbarian hinterland: Rome and northern Europe from AD 1-400. In HOWLANDS, M., LARSEN, M. \& KRISTIANSEN, K. (eds.) Centre and Periphery in the Ancient World, New Directions in Archaeology. Cambridge: Cambridge University Press, 1987.

HOWLANDS, $M$. Centre and periphery: a review of a concept. In HOWLANDS, M., LARSEN, M. e KRISTIANSEN, K. (eds.) Centre and Periphery in the Ancient World, New Directions in Archaeology. Cambridge: Cambridge University Press, 1987.

RENFREW, C. Introduction: peer polity interaction and social political change. In RENFreW, C. C CHERRY, J. F. (eds.) Peer Polity and Social Political Change, New Directions in Archaeology. Cambridge: Cambridge University Press, 1986.

WELLS, P. S. Tradition, Identity, and Change. In SCHORTMAN, E. M. e URBAN, P. A. (eds.) Resources, Power, and Interregional Interaction, Interdisciplinary Contributions to Archaeology. New York: Plenum Press, 1992.

WHEELER, M. Rome Beyond Imperial Frontiers. London, 1954. 

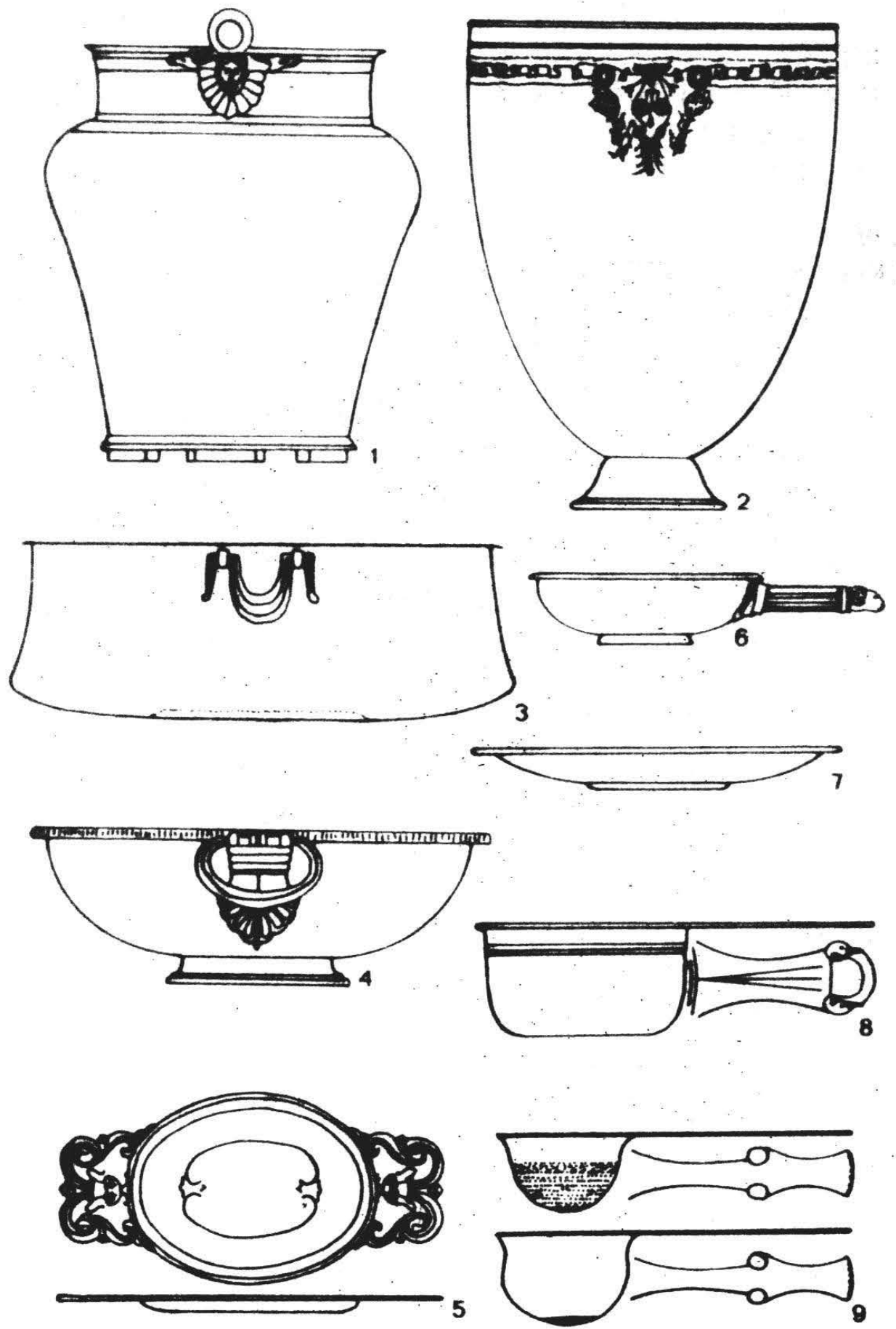

J.L. M. Castro

Fig. 1. Alguns tipos de vasilhame de luxo romano (bronze) encontrados em tumbas principescas da Germânia Livre. 


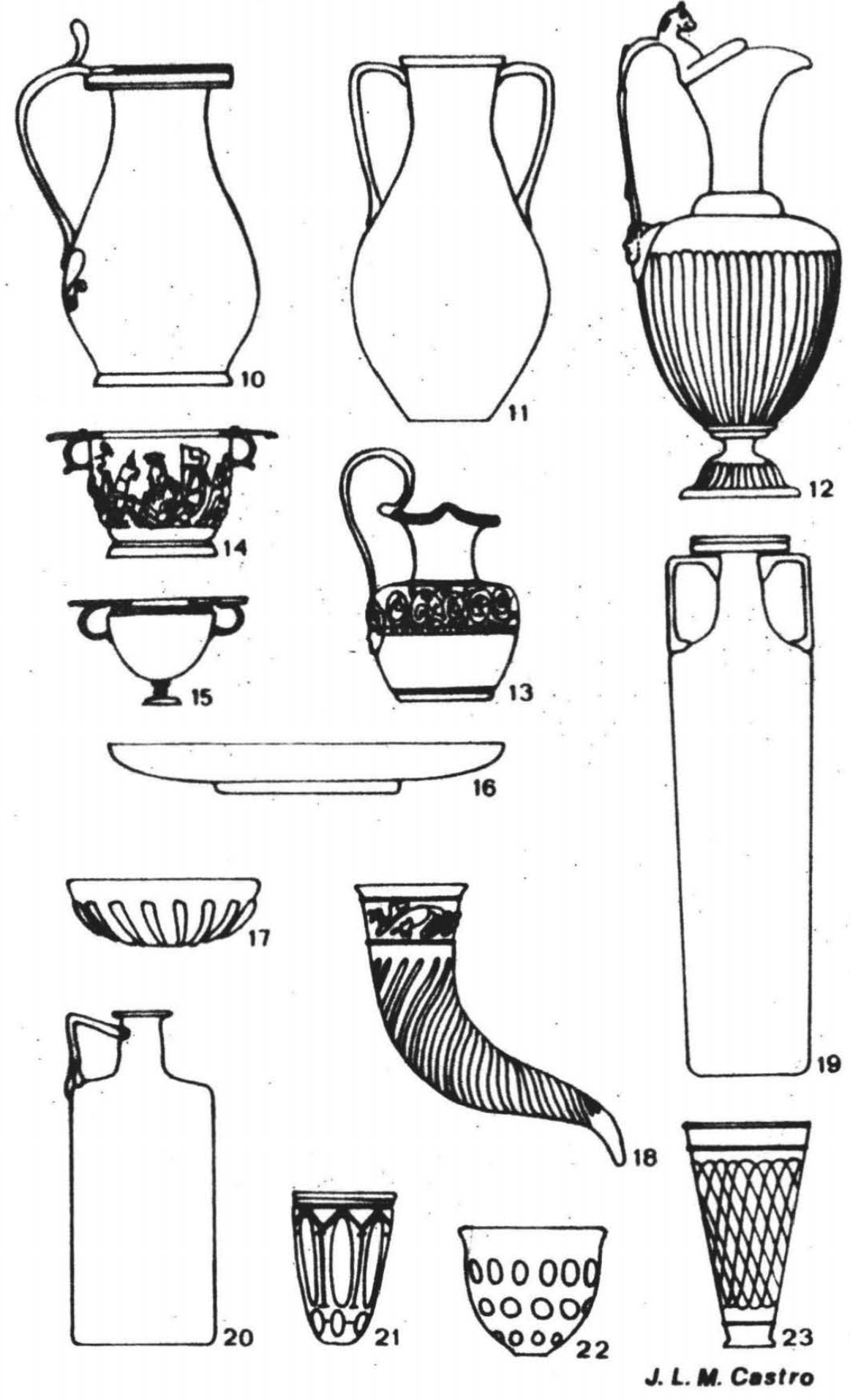

Fig. 2. Alguns tipos de vasilhame de luxo romano encontrados em tumbas principescas da Germânia Livre: n.s. 10 a 13, bronze; n.s. 14 e 15, prata; nes. 16 a 23 , vidro. 